\title{
CARACTERIZAÇÃO MORFOLÓGICA, FREQUÊNCIA DE COLHEITA E ENSILAGEM DE PALMA FORRAGEIRA: UMA REVISÃO
}

\author{
SILVA, Alex Lopes da ${ }^{1}$ \\ SOUSA, Dalva Batista de ${ }^{2}$ \\ AMORIM, Diego Sousa ${ }^{3}$ \\ SANTOS, Marilania da Silva ${ }^{1}$ \\ SILVA, Kleitiane Balduino da ${ }^{1}$ \\ NASCIMENTO, Romilda Rodrigues do ${ }^{4}$
}

RESUMO: Objetivou-se obter informações atuais sobre morfologia, frequência de colheita e ensilagem de palma forrageira. $\mathrm{O}$ crescimento e o desenvolvimento satisfatório na palma forrageira dependem da combinação adequada do manejo cultural, dos fatores ambientais e do potencial genético da variedade. A colheita é realizada com 1,5 a 2 anos ou mais, e dependendo do desenvolvimento da cultura de acordo as condições do solo e clima, possivelmente poderá ser feito o corte anual. Recursos de utilização de irrigação em pequenas quantidades e frequência pode aumentar a frequência de corte. Existem muitas variações nas características morfologias, e quando é priorizado acréscimo na produção de matéria seca em toneladas por hectare a cada dois anos, deve-se priorizar a seleção de clones de maior altura e largura da planta. Por apresentar cladódios ricos em carboidratos solúveis e água, antioxidantes, fibras dietéticas, vitaminas e apresentar massas viscosas na água devido a mucilagem, a palma forrageira pode ser ensilada. A frequência de colheita depende da necessidade dos produtores. A colheita influência nas características morfológicas. A palma pode ser ensilada em diferente frequência de corte, no entanto.

Palavras-chave: Conservação forrageira. Produtividade. Semiárido.

\section{MORPHOLOGICAL CHARACTERIZATION, FREQUENCY OF HARVEST AND SILAGE OF SPINELESS CACTUS: A REVIEW}

\begin{abstract}
SUMMARY: The objective was to obtain current information on morphology, harvest frequency and silage of spineless cactus. Satisfactory growth and development in forage palm depend on the appropriate combination of cultural management, environmental factors and the genetic potential of the variety. Harvesting takes place 1.5 to 2 years or more, and depending on the development of the crop according to soil and climate conditions, it may be possible to make the annual cut. Features of irrigation use in small quantities and frequency can increase the cutoff frequency. There are many variations in the morphological characteristics, and when prioritizing the increase in dry matter production in tons per hectare every two years, the selection of clones of greater height and width of the plant should be prioritized. Because cladodes rich in soluble carbohydrates and water, antioxidants, dietary fibers, vitamins and present viscous masses in the water due to mucilage, the forage palm can be silage. The frequency of harvest depends on the need of the producers. Harvest influence on morphological characteristics. The palm may be ensiled at different cutting frequency, however.
\end{abstract}

Keywords: Forage Conservation. Productivity. Semiarid.

\footnotetext{
${ }^{1}$ Discente de doutorado em zootecnia pela Universidade Federal da Paraíba, CCA, UFPB-Areia, PB.

${ }^{2}$ Engenheira Agrônoma

${ }^{3}$ Discente de doutorado em zootecnia pela Universidade Federal do Ceará, Campus do PICI, UFC-Fortaleza, CE.

${ }^{4}$ Pós -graduanda do Mestrado em Zootecnia pela Universidade Federal de Campina Grande, Campus de Patos, UFCG - Patos, PB.
} 


\section{INTRODUÇÃO}

A palma forrageira é a cactácea com maior potencial produtivo explorado na alimentação animal no Semiárido, pois é um importante recurso forrageiro nos períodos de estiagens, que persiste nestas condições ambientais (RAMOS et al., 2011). As variedades Opuntia e Nopalea podem produzir em até 50-60 vezes mais forragem por área que pastagens nativas (DUBEUX JUNIOR. et al., 2015), é uma valiosa forragem durante a estação seca, dada a sua suculenta e estrutura vegetativa rica em água (GROBLER et al., 2010). Dificilmente obtém-se uma outra planta com opção de forragem em nível semelhante de produtividade de MS e concentração de energia no ambiente (DUBEUX JUNIOR et al., 2006).

Por ser considerada uma reserva estratégica de forragem, neste caso, a frequência de corte da palma forrageira pode variar conforme a necessidade do produtor e das condições climáticas (SANTOS et al., 2011). Ramos et al. (2014) verificando a caracterização técnica dos sistemas de produção de palma forrageira, observaram que os produtores realizam a colheita nas frequências de 35,30\% menos de 1 ano, 52,90\% de 2 a 3 anos e 11,80\% mais de três anos. Já Almeida (2011) observou que a colheita da palma forrageira é realizada de um a três anos ou quando se faz necessário alimentar os rebanhos. Avaliações morfológicas podem permitir uma estimação da produção antes mesmo de efetuar a colheita.

Estudos de relação entre as características, tais como altura da planta, largura da planta, índice de área do cladódio, comprimento do cladódio e o rendimento da planta pode representar um dado de grande importância para a compreensão da resposta da palma forrageira às condições do ambiente de cultivo em que se encontra (PINHEIRO et al., 2014). As informações obtidas nos estudos morfológicos permitem o acompanhamento do acúmulo de forragem e uma estimativa de sua qualidade, os quais podem ser melhorados com a adequação de práticas de manejo ao longo do ciclo da cultura (COSTA et al., 2012). E assim ser colhida e fornecida aos animais, porém o seu uso é limitado, devido sua alta degradabilidade ruminal, causando efeitos laxantes (GUSHA et al., 2015a). Necessitando de ser fornecida em conjunto com uma fonte de fibra.

São necessárias estratégias para o fornecimento da palma forrageira, e por ser uma planta rica em açúcares e fibras solúveis (NEFZAOUI et al., 2013) pode ser ensilada (ÇÜREK e ÖZEN, 2004) ou também em conjunto com fenos de leguminosas (GUSHA et al., 2015b) ou ainda, associada a melaço e subproduto e farelos com finalidade de ser utilizada como alternativa de reduzir o uso de concentrado para ovinos (NEFZAOUI et al., 2013). Neste sentido, objetivou-se obter informações atuais sobre morfologia, frequência de colheita e ensilagem de palma forrageira. 


\section{PRODUÇÃO E FREQUÊNCIA DE COLHEITA}

O cultivo da palma forrageira geralmente dispende de períodos longos em que permite uma colheita a cada dois anos. Isso pode ser explicado devido a principais regiões produtoras de palma forrageira apresentarem distribuição pluviométrica irregulares e concentrada em um pequeno período, favorecendo a curtos períodos pleno de crescimento das raízes (CUNHA et al., 2012). Pois, o sistema radicular consiste em rede de raízes finas na camada superficial do solo (até 10-20 cm) adaptada para absorver a água de baixas precipitação pluviais e até do orvalho, fato que aliado ao metabolismo CAM, caracterizando uma vantagem em locais de índice pluviométrico baixo (OLIVEIRA et al., 2010). Sob estresse severo, a palma forrageira pode expandir suas raízes para as camadas mais profundas onde sinais químicos são enviados das raízes para a parte aérea afim de regular a dinâmica estomática dos cladódios (PRIMO, 2013). Apesar da adaptação as condições ambientais em que se encontra, o ciclo de colheita pode ser reduzido.

O crescimento e o desenvolvimento satisfatório na palma forrageira, dependem da combinação adequada do manejo cultural, dos fatores ambientais e do potencial genético da variedade (OLIVEIRA et al., 2010). Conforme Galvão Júnior et al. (2014) a colheita é realizada com cerca de 1,5 a 2 anos ou mais, e dependendo do desenvolvimento da cultura de acordo as condições do solo e clima, possivelmente poderá ser feito o corte anual. Dessa forma a produtividade da palma forrageira pode permitir colheitas em diferentes frequências (Tabela 1).

Tabela 1. Levantamento de diferentes estudos com palma forrageira

\begin{tabular}{|c|c|c|c|c|}
\hline Clones & ${ }^{1}$ Densidade & Frequência (dias) & ${ }^{2}$ Produção & Autor \\
\hline IPA & & & 10,7 & \\
\hline Miúda & 31.250 & 745 & 11,5 & Silva et al. (2015) \\
\hline Mexicana & & & 15,6 & \\
\hline Clone 20 & 40.000 & 730 & 33,7 & Dubeux Jr. et al. (2006) \\
\hline Gigante & 24.000 & 650 & 8,84 & $\begin{array}{l}\text { Padilha Junior et al. } \\
\qquad \text { (2016) }\end{array}$ \\
\hline Gigante & 20.000 & 620 & 18,11 & Silva et al. (2013) \\
\hline Italiana & 20.000 & 455 & 4,96 & Ramos et al. (2011) \\
\hline *Miúda & 50.000 & 365 & 25,99 & Rego et al. (2014) \\
\hline
\end{tabular}


A maior população de plantas proporcionou maior rendimento por área. Porém, mesmo não havendo uma densidade padrão no cultivo, pode-se observar uma gama de variação entre a produção em condições de sequeiro e ciclo de colheita, torna claro a dependência das condições de cultivo (DUBEUX JUNIOR et al., 2006). Nestas condições, ao longo do seu ciclo produtivo pode sofrer modificações no crescimento e no desenvolvimento em resposta às alterações sazonais e interanuais das condições do ambiente (SILVA et al., 2015). Entretanto, de extrema importância a aplicações corretas de fertilizantes, visando obter o potencial do palmal. Pois, a resposta será condicionada por deficiências existentes ou excedentes de nutrientes antes da aplicação de nutrientes (GALIZZI et al., 2004). Um aumento do número de brotos após a intensidade de corte maximiza a produção de forragem (LIMA et al., 2016). Neste contesto, colheitas mais frequentes podem permitir maior brotação, quando deixados maior número de cladódios após o corte.

Conforme Rego et al. (2014), um sistema baseado no uso mínimo de água em sistema de irrigação por gotejamento, pode reduzir o tempo de colheita $\left(25,99 \mathrm{t} \mathrm{h}^{-1}\right.$ de matéria seca em um ano sob irrigação de $10 \mathrm{~mm} / \mathrm{mês}$ e 20 toneladas de esterco bovino, tabela 1). Porém, a utilização de recursos alimentares não convencionais disponíveis e adequados na área e a utilização da água de forma mais eficiente, é uma ótima opção para garantir a viabilidade dos animais nas regiões Semiáridas (GUSHA et al., 2015b). É importante entender que espécie de palma forrageira, apesar de pertencentes ao mesmo gênero, apresentam respostas distintas em diferentes condições de cultivo (SILVA et al., 2015). A utilização da irrigação, pode ser uma opção de redução do ciclo, no entanto, quando disponível.

\section{MORFOLOGIA E FREQUÊNCIA DE COLHEITA}

Conforme Silva et al. (2010a) estudos morfológicos fornecem informações que permitem a análise quantitativa da palma forrageira. Silva et al. (2010b) estudando a relação entre características morfológicas e produtivas de clones de palma forrageira testou 50 clones cortados aproximadamente aos 13 meses, observaram que o número de artículos variou conforme clone e ordens dos cladódios. Assim como as variações no estudo Silva et al. (2015) avaliando crescimento e produtividade de palma forrageira Tabela 2. 
Tabela 2. Comparação de característica de crescimento de clones de palma forrageira (IPA - IPA Sertânia, MIU - Miúda, OEM - Orelha de Elefante Mexicana) aos dois anos após o plantio, em condições de sequeiro

\begin{tabular}{lcccccccc}
\hline Clone & AP & LP & NCP & NC1 & NC2 & NC3 & NC4 & IAC \\
\hline IPA & $69,44 a \mathrm{~b}$ & 84,89 & $13,67 \mathrm{~b}$ & 4,56 & $7,11 \mathrm{~b}$ & $1,33 \mathrm{~b}$ & $0,00 \mathrm{~b}$ & 0,93 \\
MIU & $68,11 \mathrm{~b}$ & 88,44 & $35,44 \mathrm{a}$ & 4,78 & $12,78 \mathrm{a}$ & $11,67 \mathrm{a}$ & $3,89 \mathrm{a}$ & 0,89 \\
OEM & $80,56 \mathrm{a}$ & 101,78 & $14,11 \mathrm{~b}$ & 4,00 & $1,78 \mathrm{~b}$ & $7,33 \mathrm{~b}$ & $0,00 \mathrm{~b}$ & 1,75 \\
\hline
\end{tabular}

Fonte: Silva et al. (2015).

AP - Altura de plantas (cm); LP - largura de plantas (cm); NCP - número de cladódios por planta (unidades); NC1 número de cladódios de $1^{\mathrm{a}}$ ordem (unidades); $\mathrm{NC} 2$ - número de cladódios de $2^{\mathrm{a}}$ ordem (unidades); $\mathrm{NC} 3$ - número de cladódios de $3^{\mathrm{a}}$ ordem (unidades); $\mathrm{NC} 4$ - número de cladódios de $4^{\mathrm{a}}$ ordem; e IAC - índice de área do cladódio $\left(\mathrm{m}^{2}\right)$. Médias seguidas pela mesma letra dentro de uma mesma variável não se diferenciam estatisticamente entre si pelo teste de Tukey ao nível de 5\% de probabilidade.

Maiores números de artículos foram obtidos para o clone Miúda, pois plantas pertencentes ao gênero Nopalea sp. apresentam maior quantidade de artículos, porém os cladódios são menores, quando comparadas às do gênero Opuntia sp., (CAVALCANTE et al., 2014). Quando tem maior número de artículos é secundário, pode ser devido a planta apresentar vários artículos primários, estes são responsáveis pela emissão de novos artículos (secundário), já os artículos primários são originados de uma um único cladódio, denominada mãe (SILVA et al., 2010b). Entretanto, a palma Miúda pode expressar em menor produtividade, por apresentar cladódios menores (TOBÍAS et al., 2010). Isso permite uma menor área de exposição de cladódio para troca de CO2 (NOBEL, 1988). Uma concentração de tecido fotossintético é devido ao maior número de células mesófilas por unidade de área (SILVA et al., 2010a). Quando a área de cladódio é maior, favorece o crescimento das plantas, uma vez que os cladódios fotossintetizem e consequentemente afetam a produção de biomassa (LIMA et al., 2016).

Pinheiro et al. (2014) em estudo com correlações do índice de área do cladódio com características morfogênicas e produtivas da palma forrageira cortadas com mais de 4 anos, determinaram que a variabilidade do rendimento da palma forrageira é mais influenciada pelo número total de cladódios, independentemente do clone avaliado (IPA Sertânia, Miúda e Orelha de Elefante Mexicana), os autores afirma ainda que o perímetro médio dos cladódios de terceira ordem, comprimento e perímetro dos cladódios de quarta ordem, são as variáveis mais importantes na expressão do índice de área do cladódio do clone Miúda de palma forrageira (Nopalea cochenillifera). Já Silva et al. (2010b) afirmam que priorizando acréscimo na produção de matéria seca em toneladas por hectare a cada dois anos, deve-se priorizar a seleção de clones de maior altura e largura da planta. É possível a selecionar de forma indireta variedades mais produtivas por meio de caracteres morfológicos (NEDER et al., 2013). 
Nas avaliações de palma forrageira, a maioria dos estudos versa sobre a produção de massa seca e pesquisas dessa natureza são destrutivas, cujos dados somente podem ser obtidos a partir do segundo ano de plantio, neste caso o conhecimento das taxas de crescimento pode ser uma ferramenta usual no estudo do desenvolvimento destas plantas (CUNHA et al., 2012). E se tratando de frequência de corte, existem variações na composição dos cladódios, como observado por Çürek e Özen (2004), onde a determinação da composição de cladódios jovens foi de 9,39, 4,86, 6,23, 1,65, 59,72\% de MS, PB FB, EE, e NFE respectivamente, já para cladódios maduros 11,34 3,55 7,11 2,49 58,28\% de MS, PB, FB, EE e NFE respectivamente. Baixos teores de matéria seca podem ser associados à idade da planta o que contribui para maior umidade dos artículos da planta (DUBEUX JUNIOR et al., 2010). Dessa forma, maior frequência de colheita promove maior disponibilidade de água nos cladódios, pois as plantas contem maior quantidade de cladódios jovens.

A intensidade do corte também pode influenciar na frequência, conforme Lima et al. (2016) avaliando o efeito de diferentes intensidades de corte e anos de colheita sobre as características morfológicas e produtividade de palma irrigada com 2,5mm por semana na cv. Gigante com alta densidade de plantio e 12 meses de rebrota, concluíram que o corte deixando os cladódios secundários na colheita promoveu mais cladódios por planta e uma maior produtividade de forragem e promove uma maior sustentabilidade da palma Gigante sob irrigação e que as características morfológicas mais importantes também foram influenciadas por menores intensidades de corte. De forma semelhante (TOBÍAS et al., 2010) obtiveram maior frequência das colheitas quando pequenas quantidades de rebrotas foram colhidos.

Estudos com ciclos menores foram testados por Nascimento (2008), que testando com palma em condições de campo e adubação fosfatada em variação de 100 a $250 \mathrm{~kg} \mathrm{ha}^{-1}$, resultou em até 5,61 artículos por planta aos 180 dias de idade, próximo do encontrado por Já Dubeux Junior et al. (2010) trabalhando com Clone IPA- 20 irrigada colhida aos seis meses de idade, sem aplicações de adubações fosfatadas, que obteve 5,75 cladódios por plantas distribuídos 2, 3 e 0,75 como primeiro, segundo e terceira ordem respectivamente. Entretanto, os estudos deixam claro que para a obtenção de ciclos mais curtos, necessita de maiores investimentos no cultivo de palma forrageira.

\section{SILAGEM DE PALMA FORRAGEIRA}

Os cladódios da palma são ricos em carboidratos solúveis e água, mais pobre em nitrogênio (NEFZAOUI et al., 2013) ricos em antioxidantes, fibras dietéticas, vitaminas (A, Bcomplexo e C) e minerais (Ca, Mg e Fe) (KALEGOWDA et al., 2016). Segundo Neves et al. 
(2014) a palma Gigante (Opuntia fícus indica, Mill) apresenta na sua constituição 11,21\% de MS, 4,91\% de PB, 53,35\% de CNF e 28,35\% de FDN e lignina 3,53\% na palma Miúda (Nopalea cochenillifera) $12,35 \%$ de MS, 3,55\% de PB, $60 \%$ de CNF e 24,49\% de FDN. Considerada uma excelente fonte de energia (WANDERLEY et al., 2002; MELO et al., 2003). Assim a palma forrageira pode ser ensilada.

Após a ensilagem, os carboidratos solúveis e ambiente na ausência de ar, permitem que as bactérias lácticas se multiplicam rapidamente, produzindo ácidos lático e acético, provocando rápida queda no $\mathrm{pH}$, proporcionalmente ao teor de carboidratos solúveis do material ensilado (VAN SOEST, 1994). Como a palma é uma excelente fonte de carboidratos, esta fermentação não é um impasse. Porém, pelo elevado teor de umidade, 85 a 92\% de água (CANTWELL, 2001), esse excesso de umidade presente aumenta o risco de fermentações indesejáveis com maior produção dos ácidos acéticos e butíricos, nitrogênio amoniacal, amidas e aminas (MCDONALD et al., 1991) o que compromete a qualidade da silagem. Entre tanto, a palma forrageira é caracterizada pela sua produção de mucilagem (KIM et al., 2013).

Mucilagem é um carboidrato complexo, que faz parte da fibra dietética (KIM et al., 2013). Está distribuído nos cladódios e frutas de Opuntia spp. (SAENZ, et al., 1998). Este complexo de polissacarídeos de alto peso molecular, e ocorrência natural, ainda possui estrutura detalhada desconhecida, que tem a capacidade de formar massas viscosas na água e tipicamente heterogênea na composição e serve como metabólitos secundários das plantas de fundamental importância para as cactáceas, devido desempenhar um papel significativo na manutenção do equilíbrio das células vegetais, tolerância à geada, transporte de água, cicatrização de ferida, interações de patógenos planta-hospedeiro e reservas de carboidratos (BHARAT et al., 2011). Por formar uma massa viscosa na agua, pode tornar viável a sua ensilagem, ou ser ensilada com uma desidratação a sombra (Tabela 3).

Observa que ocorreu pouca variação entre os cladódios jovens e maduros, isto fica claro que pode ser ensilado quando realizados uma maior frequência de colheita, pois há uma maior concentração de cladódios jovens. 
Tabela 3. Teores de matéria seca (MS), proteína bruta (PB), fibra bruta (FB), extrato não nitrogenado $(\mathrm{ENN})$, extrato etéreo (EE), ácidos orgânicos e pH de silagem de cladódios palma forrageira em diferentes estádios de maturação

\begin{tabular}{|c|c|c|c|c|c|}
\hline \multirow{2}{*}{ Tratamentos } & \multicolumn{5}{|c|}{ Variáveis } \\
\hline & MS & $\mathbf{P B}^{2}$ & FB & ENN & $\mathbf{E E}$ \\
\hline${ }^{1}$ Cladódios jovens & 20,59 & 3,68 & 8,11 & 57,09 & 2,33 \\
\hline \multirow[t]{2}{*}{${ }^{1}$ Cladódios maduros } & 19,69 & 3,24 & 6,48 & 59,85 & 1,87 \\
\hline & \multicolumn{5}{|c|}{ Ácidos orgânicos² } \\
\hline Tratamentos & Ácido lático & Ácid & ico & Ácido butírico & $\mathrm{pH}$ \\
\hline${ }^{1}$ Cladódios jovens & 2,59 & & & 0,34 & 4,08 \\
\hline${ }^{1}$ Cladódios maduros & 3,20 & & & 0,31 & 3,83 \\
\hline
\end{tabular}

Fonte: Çürek e Özen (2004).

${ }^{1}$ Cladódios desidratados até 35\% de MS; ${ }^{2}$ Base na matéria seca.

Segundo McDonald et al. (1991), as silagens consideradas satisfatórias devem apresentar valores de fermentação de ácido lático iguais ou superiores a 5,0\% da matéria seca; ácido butírico em proporções iguais ou superiores a $0,1 \%$ é um indicativo de que houve fermentação indesejável durante a ensilagem e que é permitido até $0,8 \%$ de ácido acético na matéria seca, já o $\mathrm{pH}$ que variam entre 3,7 e 4,2 e silagens mal preservadas possuem alto $\mathrm{pH}$, entre 5,0 e 7,0, as quais podem permitir concentrações consideráveis de ácido acético e butírico. Em discordância de Tomich et al. (2003), relataram teores de ácido butírico no máximo 0,09\% na matéria seca e consideram que silagem bem fermentada, com teores máximo 3,5\% de ácido acético na matéria seca. Mota et al. (2011) o ácido acético também conserva a massa ensilada, porém, em concentrações acima de $0,8 \%$ é um indicativo de que houve alterações indesejáveis no processo de ensilagem. França et al. (2011) afirmam que o $\mathrm{pH}$ de 3,8 a 4,2 possibilita a conservação desejada da massa ensilada. Entre tanto, Çürek e Özen (2004) avaliaram a silagem de palma em diferentes estádios fenológico (Tabela 3), classificaram como de boa qualidade. Já Mokoboki et al. (2016) avaliando Opuntia variedade Roedtan colhida aos dois anos, desidratada e adicionadas melaço e Lactobacilos, encontram teores de 8,7, 6,86, 25,85 e 6,64\% para MS, PB, FDN e EE respectivamente e 5,65\% ácido lático e pH de 3,08. Valores satisfatório do ácido lático, pode ter sido em decorrência da ação do melaço e lactobacilos, porém um abaixamento no pH diferente apresentado na tabela 3.

Um ponto importante é a compactação, aumento da densidade de compactação da massa no interior do silo melhora o processo fermentativo, pois promove a redução do $\mathrm{pH}$ e dos teores de nitrogênio amoniacal (TAVARES et al., 2009). A palma forrageira possivelmente não permite 
uma compactação semelhante as plantas forrageiras consolidadas, devido risco de perdas por efluentes. Gusha et al. (2015b) neste contexto, pode ser ensilagem cladódios de elevado teor de humidade com fenos secas de forragem, isto pode melhorar o teor de matéria seca do alimento para animais e ao mesmo tempo equilibrar as deficiências observadas nos ingredientes usados.

Nefzaoui et al. (2013) testaram cladódios de Opuntia ficus-indica f. Inermis ensilado na proporção de $35 \%$ com farelos, afim de diminuir uso de feno de aveia e/ou concentrado usados na alimentação de ovinos na Tunísia, concluíram que o material ensilado pode ser usado para substituir feno total ou parcialmente sem afetar o crescimento de cordeiro e a qualidade da carne. Gusha et al. (2015a) avaliando in vivo em cabras o efeito de alimentação de cladódios frescos de palma selvagem ensilada em $67 \%$ nos seguintes tratamentos, palma-Acacia angusitissima (CAAS), palma-Leucaena leucocephala (CLLS), palma-Calliandra calothyrsus (CCCS) e palmaMacroptilium atropurpureum (CMAS) utilizados como suplementos a uma dieta basal de feno de Pennisetum purpureum, sendo que para cada $20 \mathrm{~kg}$ dos tratamentos, foi adicionado 2 litros de melaço na ensilagem, concluíram que a palma pode servir como um elo entre forragem de leguminosas e feno, e as silagens melhoram o fluxo de proteína microbiana e aumentou o suprimento de aminoácidos para manutenção, crescimento e produção.

\section{CONSIDERAÇÕES FINAIS}

A frequência de colheita depende da necessidade dos produtores, porém a produtividade depende dos fatores ambientais, tratos culturais e de investimentos utilizados.

A frequência e colheita influência nas características morfológicas. Assim uma avaliação previa de medidas morfológicas por meio de uma amostragem, permite estimar previamente a produtividade da palma forrageira. A palma pode ser ensilada em diferente frequência de corte.

\section{REFERÊNCIAS}

ALMEIDA, J. A palma forrageira na região semiárida do estado da Bahia: diagnóstico, crescimento e produtividade. 2011. 95f. (Tese de Doutorado). Universidade Federal do Recôncavo da Bahia. Cruz das Almas - BA.

BHARAT, M. R.et al.Isolation and characterization of remusatia vivipara tubers mucilage. International Journal of Pharmacy and Biological Sciences, v.1, p.457-461, 2011.

CANTWELL, M. Manejo pós-colheita de frutas e verdura de palma forrageira. In: Barbera, G.; Inglese, P.; Barrios, E. P. (Ed.). Agroecologia, cultivo e usos da palma forrageira. Paraíba: SEBRAE/PB, p.123-139. 2001. 
CAVALCANTE, L. A. D.et al. Respostas de genótipos de palma forrageira a diferentes densidades de cultivo. Pesquisa Agropecuária Tropical, v.44, n.4, p.424-433, 2014.

COSTA, N. L.; GIANLUPPI, V.; MORAES, A. Produtividade de forragem e morfogênese de Trachypogon vestitus, durante o período seco, em área de cerrado. Revista Trópica - Ciências Agrárias e Biológicas, n.6, p.93-103, 2012.

CUNHA, D. N. F. V.et al. Morfometria e acúmulo de biomassa em palma forrageira sob doses de nitrogênio. Revista Brasileira de Saúde e Produção Animal, v.13, n.4, p.1156-1165, 2012.

ÇÜREK, M.; ÖZEN, N. Feed Value of Cactus and Cactus Silage. Turkish Journal of Veterinary and Animal, v.28, 633-639, 2004.

DUBEUX JUNIOR, J. C. B.et al. Adubação mineral no crescimento e composição mineral da palma forrageira - Clone IPA-201. Revista Brasileira de Ciências Agrárias, v.5, n.1, p.129$135,2010$.

DUBEUX JUNIOR, J. C. B.et al. Productivity of Opuntia ficus-indica (L.) Miller under different $\mathrm{N}$ and $\mathrm{P}$ fertilization and plant population in north-east Brazil. Journal of Arid Environments, v.67, p.357-372, 2006.

DUBEUX JUNIOR, J. C. B. et al.Forage potential of cacti on drylands. Acta Horticulturae (ISHS), Leuven, v.1, n.1067-24, p.181-186, 2015.

FRANÇA, A. F. S.et al. Características fermentativas da silagem de híbridos de sorgo sob doses de nitrogênio. Ciência Animal Brasileira, v.12, n.3, p.383-391, 2011.

GALIZZI, F. A.; FELKER, P.; GARDINER, C. G. D. Correlations between soil and cladode nutriente concentrations and fruit yield and quality in cactus pears, Opuntia ficus indica in a traditional farm setting in Argentina. Journal of Arid Environments, v.59, p.115-132, 2004.

GALVÃO JÚNIOR, J. G. B.et al. Palma forrageira na alimentação de ruminantes: cultivo e utilização. Acta Veterinaria Brasilica, v.8, n.2, p.78-85, 2014.

GROBLER, S. M.; DEARLOVE, K.; SCHOLTZ, M. M. Palatibility of Opuntia varieties available in South Africa for dryland sheep. South African Journal of Animal Science, v.40, n.5, p.495-498, 2010.

GUSHA, J.et al. The effect of Opuntia ficus indica and forage legumes baseddiets on goat productivity in smallholder sector in Zimbabwe. Small Ruminant Research, v.125, p.21-25, $2015 b$.

GUSHA, J.et al. Effect of feeding cactus-legume silages on nitrogen retention, digestibility and microbial protein synthesis in goats. Animal Feed Science and Technology, 7p. 2015a.

KIM, J. H.et al. Mucilage removal from cactus cladodes (Opuntia humifusa Raf.) by enzymatic treatment to improve extraction efficiency and radical scavenging activity. Food Science and Technology, v.51, p.337-342, 2013.

LIMA, G. F. C.et al. Morphological characteristics and forage productivity of irrigated cactus pear under different cutting intensities. Revista Caatinga, v.29, n.2, p.481-488, 2016. 
MCDONALD, P.; HENDERSON, A. R.; HERON, S. J. E. The biochemistry of silage. $2^{\text {a }}$ ed. Chalcombe Publications. Marlow. 1991, 340 pp.

MELO, A. A. S.; FERREIRA, M. A.; VERAS, A. S. C. Substituição do farelo de soja por uréia e palma forrageira (Opuntia fícus indica Mill) em dietas para vacas em lactação. I. Desempenho. Revista Brasileira de Zootecnia, v.32, n.3, p.727-736, 2003.

MOKOBOKI, K.; SEBOLA, N.; MATLABE, G. Effects of molasses levels and growing conditions on nutritive value and fermentation quality of Opuntia cladodes silage. Journal of Animal \& Plant Sciences, v.28, n.3, p.4488-4495, 2016.

MOTA, A. D. S.et al. Perfil de fermentação e perdas na ensilagem de diferentes frações da parte aérea de quatro variedades de mandioca. Revista Brasileira de Zootecnia, v.40, n.7, p.14661473, 2011.

NASCIMENTO, J. P. Caracterização morfométrica e estimativa da produção de Opuntia fícus-indica Mill. sob diferentes arranjos populacionais e doses de fósforo no semiárido da Paraíba, Brasil. 2008. 47p. Dissertação (Mestrado).Campina Grande: UFCG, 2008.

NEDER, D. G.et al. Correlations and path analysis of morphological and yield traits of cactus pear accessions. Crop Breeding and Applied Biotechnology, v.13, n.1, p.203-207, 2013.

NEFZAOUI, A.et al. Silage Composed of Opuntia ficus-indica f. inermis Cladodes, Olive Cake and Wheat Bran as Alternative Feed for Barbarine Lamb. Acta Horticulture, v.995, p.297-302, 2013.

NEVES, A. L. A.et al. Tabelas nordestinas de composição de alimentos para bovinos leiteiros. Embrapa 1.ed. Brasília, DF, 2014. 184p.

NOBEL, P. S. Environmental Biologyof Agaves and Cacti. Cambridge UniversityPress, Cambridge, 270p. 1988.

OLIVEIRA, F. T.et al. Palma forrageira: adaptação e importância para os ecossistemas Áridos e Semiáridos. Revista Verde, v.5, n.4, p.27-37, 2010.

PADILHA JUNIOR, M. C.et al. Características morfométricas e rendimento da palma forrageira 'Gigante' sob diferentes adubações e configurações de plantio. Revista Verde de Agroecologia e Desenvolvimento Sustentável, v.11, n.1, p.67-72, 2016.

PINHEIRO, K. M.et al. Correlações do índice de área do cladódio com características morfogênicas e produtivas da palma forrageira. Pesquisa Agropecuária Brasileira, v.49, n.12, p.939-947, 2014.

PRIMO J. T. A. Dinâmica de água no solo e eficiência no uso de água em clones de palma forrageira no Semiárido Pernambucano. 2013. 106f. (Dissertação mestrado). Universidade Federal do Pernambuco. Serra Talhada - PE. 2013.

TOBIAS, H. M. R.et al.Nopalito and forage productivity of Opuntia spp. and Nopalea sp. (Cactaceae) growing under greenhouse hydroponics system. Journal of Food, Agriculture \& Environment, Helsink, v.8, n.(3\&4), p.660-665, 2010. 
RAMOS, J. P. F.et al. Crescimento vegetativo de Opuntia ficus-indica em diferentes espaçamentos de plantio. Revista Caatinga, v.24, n.3, p.41-48, 2011.

RAMOS, J. P. F.et al. Caracterização técnica dos sistemas de produção de palma forrageira em Soledade, PB. Agropecuária Técnica, v.35, n.1, p.23-30, 2014.

REGO, M. M. T.et al. Morfologia e rendimento de biomassa da palma Miúda irrigada sob doses de adubação orgânica e intensidades de corte. Revista Científica de Produção Animal, v.16, n.2, p.118-130, 2014.

SAENZ, C.et al. Cactus pear fruit: a new source for a natural sweetner. Plant Foods for Human Nutrition, v.52, p.141-149, 1998.

SANTOS, M. V. F.et al. 2011. Manejo da palma forrageira, In: CONGRESSO BRASILEIRO DE PALMA E OUTRAS CACTÁCEAS, 2., Garanhuns. Anais [...]. Garanhuns: Pernambuco, 2011. $15 \mathrm{p}$.

SILVA, J. A.et al. Composição bromatológica de palma forrageira cultivada em diferentes espaçamentos e adubações química. Revista Brasileira de Ciências Agrárias, v.8, n.2, p.342$350,2013$.

SILVA, M. G. S.et al. Anatomy of different forage cacti with contrasting insect resistance. Journal of Arid Environments, v.74, p.718-722, 2010a.

SILVA, N. G. M.et al. Relação entre características morfológicas e produtivas de clones de palma-forrageira. Revista Brasileira de Zootecnia, v.39, n.11, p.2389-2397, 2010 b.

SILVA, T. G. F.et al. Crescimento e produtividade de clones de palma forrageira no Semiárido e relações com variáveis meteorológicas. Revista Caatinga, v.28, n.2, p.10-18, 2015.

TAVARES, V. B.; PINTO, J. C.; EVANGELISTA, A. R. Efeitos da compactação, da inclusão de aditivo absorvente e do emurchecimento na composição bromatológica de silagens de capimtanzânia. Revista Brasileira de Zootecnia, v.38, n.1, p.40-49, 2009.

TOMICH, T. R.et al. Características químicas para avaliação do processo fermentativo: uma proposta para qualificação da fermentação. Corumbá: Embrapa Pantanal. 20p. 2003. (Documentos, 57).

VAN SOEST, P. J. Nutritional ecology of the ruminants. 2.ed. Ithaca: Cornell University, 1994, 476p.

WANDERLEY, W. L.; FERREIRA, M. A.; ANDRADE, D. K. B. Palma forrageira (Opuntia fícus indica, Mipp) em substituição à silagem de sorgo (Sorghum bicolor (L.)) na alimentação de vacas leiteiras. Revista Brasileira de Zootecnia, v.31, n.1, p.273-281, 2002. 